\title{
O Tempo Vertical e a Dimensão do Poético na Cbra de Clarice Iispector: Uma Leitura Bachelardiana*
}

\author{
Maria Elisa de Oliveira**
}

Resumo: A presença marcante de uma prosa-poética na produção ficcional de Clarice Lispector possibilitou-nos exemplificar algumas noções centrais (tempo vertical e instante poético) na rica e sugestiva reflexão de Gaston Bachelard acerca do universo poético.

Palavras-chave: tempo vertical - tempo presente - instante poético-prosa-poética - literatura

Embora Gaston Bachelard afime que algumas "sínteses de objetos", tão bem realizadas pela dimensão do poético, estariam impossibilitadas de se exprimir na linguagem da prosa (Bachelard 2, p. 79), no caso da prosa clariciana, acreditamos, seguramente, que ela é também capaz de oferecer ao leitor "uma grande alegria de palavras", tanto quanto o poeta. Com isto, podemos afirmar que a prosa-poética de Clarice Lispector ${ }^{(1)}$ está povoada de "imagens-frases"(2), no dizer do pensador francês, que vão contra aquilo que é commente aceito, os lugares-comuns, criando assim expressões no- 
vas. Sua escritura ${ }^{(3)}$ confimaria, igualmente, um aspecto que é particular à poesia e que foi assinalado por Bachelard, ou seja, o começo e a novidade (Bachelard 2, p. 75) .

A linguagem de Clarice é capaz, portanto, de, como a poesia e a própria filosofia, provocar admiração, vindo ao encontro, mais uma vez, das palavras de Bachelard, para quem, "a poesia é uma admiração, exatamente no nível da palavra, na palavra e pela palavra" (id., ibidem, p. 79) .

O emprego, por exemplo, do oxímoro e do paradoxo - figuras amplamente encontradas no estilo de Clarice - não ofereceria, pois, a oportunidade de entrarmos em contato com essas "sínteses de objetos", que, pela estranheza e contraste, abalariam o leitor, arrancando-o do seu torpor?

o que dizer, então, apenas como exemplo, desta poética passagem, colhida ao acaso, e que dá título ao segundo romance da autora brasileira, O Lustre:

"Havia o lustre. A grande aranha escandescia. Olhava-o imóvel, inquieta, parecia pressentir uma vida terrível. Aquela existência de gelo. Uma vez! uma vez a um relance - o lustre se espargia em crisântemos e alegria. Outra vez - enquanto ela corria atravessando a sala - ele era uma casta semente. O lustre" (Lispector 6, p. 14) .

Na verdade, Clarice não compara o lustre com a aranha, já que se fosse assim não teríamos uma imagem (Bachelard 2, p. 74), e sim explicações e aproximações que fariam diminuir, segundo Bachelard, o impulso de uma imaginação. Aqui, ao contrário, há fusão, união entre o lustre e a aranha, entre o lustre e a flor! Recordamos aqui, a propósito, as palavras de Octavio Paz: "A imagem nunca quer dizer isto ou aquilo. Sucede justamente o contrário, (...) : a imagem diz isto e aquilo ao mesmo tempo. E mais ainda: isto é aquilo" (Paz 12, p. 231). Fis aí a inauguração de um "reino das imagens decisivas, das decisões poéticas" (Bachelard 2, p. 35) na prosapoética clariceana. Audácia da poesia apenas, única a saber unir, numa só imagem, dois objetos? Não: a prosa-poética de Clarice também consegue reinar no domínio da imaginação, livre e criativa, proporcionando a fusão entre "lustre e aranha", "lustre e flor", fazendb o leitor sonhar e, sobretudb, entrar nos castelos do devaneio(4).

Após apontarmos o elemento de poesia na obra ficcional de Clarice Lispector, é possível, como decorrência, destacar, usando os termos de Bachelard, uma "perspectiva vertical que paira sobre o instante poético", (Bachelard 3, p. 105), e que pode ser entendida tanto no sentido da profundeza quanto da altura ${ }^{(5)}$.

Mas que tempo é esse que se define e se qualifica como sendo, afinal, um tempo raro e complexo, que nada tem que ver com a duração comum, visto que esta última se dispersa, incessantemente?

Na concepsão bachelardiana, trata-se de um tempo que, ao contrário, é capaz de "transportar o ser para fora da duração comum" (id., ibidem, p. 109), colocando-o assim num outro eixo - vertical. Para isso é preciso, ainda segundo o pensador francês, trabalhar o tempo, de tal maneira, que se consiga converter a contradição em ambivalência e o sucessivo, em simultâneo, características aliás da imagem poética (Paz 12, pp. 119-138) . Nas palavras de Bachelard: "o instante poético é a consciência de uma ambivalência" (Bachelard 3, p. 104), ou ainda, "no instante poético o ser sobe ou desce, sem aceitar o tempo do mundo (...)" (id., ibidem) .

Ora, não é difícil encontrar uma certa "perspectiva vertical" na dora de Clarice Lispector e, um exame um pouco mais demorado do quinto romance da autora brasileira, A Paixão segundo G.H., de 1964, poderá ilustrar a afimação que acabamos de fazer. No entanto, essa escolha não indica exclusividade; outros romances poderiam, igualmente, servir para o mesmo propósito. O aspecto de romance-poema de A Paixão, como alguns o chamaram ${ }^{(6)}$, significando pois uma marcante "fusão entre prosa e poesia", foinos, todavia, determinante.

Vejamos então como pode se dar a inscrição material desta "perspectiva vertical" no texto em questão.

Antes, porém, de examinarmos a presença de uma verticalidade temporal em A Paixão, devemos insistir no aspecto essencialmente verbal do tempo, como um elemento que se realiza e se materializa na e pela linguagem.

A Paixão segundo G.H., narrada na primeira pessoa, é um longo e intenso monólogo interior à procura de uma compreensão. A narrativa abre 
e fecha com seis travessões indicando, nas palavras de Massaud Moisés (Moisés 7, p. 5) , a "circularidade de um poema", fazendo assim com que o início coincida com o final, à semelhança de uma serpente que engolisse a própria cauda(7) . Aqui, tudo se transfigura para dar lugar a uma "perspectiva vertical". O emprego dos recursos sintáticos e semânticos produzem um efeito incomum, como se "o fantástico fosse a realidade do mundo, a dimensão propriamente humana e não outra qualquer, transcendente" (Lispector 5, p. 5) . Com isto, espaço e tempo sofrem uma profunda transformação, criando uma atmosfera transfigurada onde, afinal, se processa a ação e também a autodescoberta da personagem-protagonista.

Na verdade, todo o romance é uma grande metáfora da peregrinação de G.H. ao encontro do seu núcleo interno. É interessante observar que a experiência insólita, vivida por G.H. (o confronto com o inseto-barata, esmagado na porta do guarda-roupa, no quarto de empregada), se passa no último andar de um edifício, mais exatamente, numa "cobertura". O local sugere já um sentido de verticalidade que se estende até atingir o quarto de empregada onde a personagem-protagonista G.H. vive uma profunda metamorfose:

"Forcei-me a me lembrar que também aquele quarto era posse minha, e dentro de minha casa: pois, sem sair desta, sem descer nem subir, eu havia caminhado para o quarto. A menos que tivesse havido um modo de cair num poço mesmo em sentido horizontal, como se houvessem entortado ligeiramente o edifício e eu, deslizando, tivesse sidb despejada de portas a portas para aquela mais alta" (idem 4, p. 49).

Em outras passagens, G.H. se refere ao quarto de empregada como "quarto-minarete", "oratório", e a sensação de que ele está ainda mais alto ou, até mesmo, desligado do resto do edifício, onde ela se situa é, frequientemente, registrada:
"O quarto parecia estar em nível incomparavelmente acima do próprio apartamento. Como um minarete. Começara então a minha primeira impressão de minarete, solto acima de uma extensão ilimitada" (Lispector 4, p. 40).

"Não ser inteiramente regular nos seus ângulos dava-lhe uma impressão de fragilidade de base como se o quarto-minarete não estivesse incrustado no apartamento nem no edifício" (id., ibidem, p. 41) .

Nesta outra passagem, "'Ah, quero voltar para a minha casa', pedi-me de súbito, pois a lua úmida me dera saudade de minha vida. Mas daquela plataforma eu não conseguia nenhum momento de escuridão e lua" (id., ibidem, p. 126), o uso de uma linguagem plurissignificativa permite que a protagonista se refira ainda ao quarto de empregada como um local suspenso ${ }^{(8)}$. Nesse mesmo quarto-minarete sentimos ressoar o aspecto da ambivalência, de que fala Bachelard ${ }^{(9)}$, sem o qual não podemos entender as noçães de instante poético e tempo vertical. Mencionando a fusão dos sentimentos vividos por G.H., por ocasião do confronto com o inseto, Benedito Nunes formula o seguinte comentário:

"Projetam-se diante dela [G.H.], em figuras mutáveis, os contrastes inconciliáveis da existência - amor e ódio, ação, violência e mansidão, crueldade e piedade, santidade e pecado, esperança e desespero, sanidade e loucura, salvação e danação, pureza e impureza, liberdade e servidão, o belo e o grotesco, o humano e o divino, o estado natural e o estado de graça, o sofrimento e a redenção, o inferno e o paraíso. Cada um desses pólos se confunde com o seu oposto, na visão abismal que reduz as diferenças e tende a suprimilas. Alegria e dor se interpenetram; presente e futuro tornam-se momentos indivisíveis da existência em ato, idêntica, abolindo a separação e a divisão" (Nunes 9, p. 59) . 
Podemos enfim dizer que G.H. experimenta todos esses sentimentos, juntos, sem que se possa afimar ainda que um viria antes ou sucederia ao outro. Nas palavras de Bachelard:

"Tal ambivalência não pode ser descrita nos tempos sucessivos, como um balanço vulgar de alegrias e pesares passageiros. Contrários tão vivos [como os de, por exemplo, A Paixão], tão fundamentais, dependem de uma metafísica imediata. Vive-se a oscilação num único instante, por êxtases e quedas que podem até estar em oposição aos acontecimentos: o desgosto de viver se apodera de nós no gozo, tão fatalmente quanto a altivez na infelicidade" (Bachelard 3, p. 188) .

Os dois pólos - o da descida e o da subida do ser (id., ibidam, p. 105) - se acham presentes em A paixão, reforçando assim um outro aspecto do instante poético, conforme entende Bachelard. No primeiro caso, bastaria lembrar o gesto extremo e último da personagem-protagonista, quando, ao levar a mão à boca, ela come da matéría viva (paródia da comunhão) representada pela barata, vivendo assim as "piores penas", intensa e profundamente (id., ibidem, p. 107) . No segundo caso, o pólo da subida, vale lembrar o comentário de Bachelard:

"Sobre o tempo vertical - ao subir - é que se consolida a consolação sem esperança, essa estranha consolação autóctone, sem protetor. Em suma, tudo que nos afasta da causa e da recompensa, tudo que nega a história íntima e o próprio desejo, tudo que desvaloriza ao mesmo tempo o passado e o futuro encontra-se no instante poético" (id., ibidkm, p. 187) .

Ora, em A Paixão segundo G.H. vemos crescer a importância do tempo presentee, dentro deste, o tempo atual, a atualidade, apesar da profunda sensação de que este tempo é, de algum modo, inalcançável:
"Eu me contorço para conseguir alcançar o tempo atual que me rodeia, mas continuo remota em relação a este mesmo instante. O futuro, ai de mim, me é mais próximo que o instante já" (10kisispector 4, p. 146) .

No seu arroubo e êxtase G.H. atinge ainda um tempo vertical, que não reconhece o valor do passado e do futuro, mas que se condensa no "hoje" e no "agora-já":

"(...) quero encontrar a redenção no hoje, no já, na realidade que está sendo e não na promessa, quero encontrar a alegria neste instante - quero o Deus naquilo que sai do ventre da barata - mesmo que isto, em meus antigos termos humanos, signifique o pior, e, em termos humanos, o infernal" (id., ibidem, p. 97).

Pela ferida ou abertura/fresta do inseto - provocada pelo esmagamento do inseto na porta do guarda-roupa - G.H. tem então a oportunidade de ver "o outro lado" do ser, do seu ser, resultado também da ruptura do espaço e do tempo, que se dá neste momento. Tem início, a partir daí, uma série de vertigens, cujo desfecho culmina no contato íntimo (manducação da barata) entre a matéria-prima e a personagem-protagonista.

Se, por outro lado, atentarmos para a opinião de Benedito Nunes, segundo a qual, Água Viva "traz a mesma obsessão da matéria primordial [o it] com que nos deparamos em A Paixão segundo G.H." (Nunes 9, p. 158), veremos que a presença de um tempo vertical poético se faz aqui, igualmente, presente. $O$ embate entre chas realidades distintas designadas pela personagem-narradora, aliás, sem nome, sugere a importância de um tempo vertical, em contraste com um tempo e uma realidade comm e ordinária:

"Será que passei sem sentir para o outro lado? O outro lado é uma vida latejantemente infernal. Mas há a transfiguração do meu terror: então entrego-me a uma pesada vida toda em símbolos pesados 
como frutas maduras. Escolho parecenças erradas mas que me arrastam pelo enovelado. Uma parte mínima de lembrança do bom senso de meu passado me mantém roçando ainda o lado de cá. (...)

Mas ninguém pode me dar a mão para eu sair: tenho que usar a grande força - e no pesadelo em arranco súbito caio enfim de bruços no lado de cá. Deixo-me ficar jogada no chão agreste, exausta, o coração ainda pula doido, respiro às golfadas. Estou a salvo? enxugo a testa molhada" (Lispector 5, p. 21-22)

Todavia, a noção de verticalidade do instante poético não pode deixar de estar ligada, particularmente na dbra de Clarice Lispector, à questão da discursividade da linguagem. Não devemos esquecer que os grandes temas encontrados na produção ficcional de Clarice - a morte, o tempo, a precariedade da vida, apenas para citar alguns - não se desvinculam das suas "preocupações com a linguagem e a natureza específica da ficção da vida" (Sá 13, p. 87) .

Quanto a Bachelard, não percebemos que o autor tenha dispensado, ao analisar e investigar a gênese poética e a noção de tempo vertical ${ }^{(11)}$, um tratamento mais amplo às questões da linguagem propriamente dita, ou mesmo, à natureza específica da ficção. Ora, no caso da autora brasileira essa abordagem é indispensável ${ }^{(12)}$.

Assim, um dos problemas que devemos enfrentar na prosa-poética de Clarice é a conciliação entre a verticalidade, característica do instante poético, instantâneo e pleno, e o tempo do discurso. Em outras palavras, como "fundir" o instante poético (vertical), com a capacidade de dar, instantaneamente, uma visão do universo e o segredo/mistério de uma alma, e a discursividade (linear) da linguagem, ou, enfim, como dizer o instante.

A própria Clarice, lamentando o aspecto da "discursividade limitadora" da linguagem, confessa:

"Novo instante em que vejo o que vai se seguir. Embora para falar do instante de visão eu tenha que ser mais discursiva que o instante: muitos instantes passarão antes que eu desdobre e esgote a complexidade una e rápida de um relance" (Lispector 5, p. 64) .

Um recurso para fazer face a essa insuficiência seria, como observa Olga de Sá, "(...) desejar para a linguagem, os processos da pintura e até a fotografia (...)" (Sá 13, p. 158), como acontece em Água Viva. Neste texto, escrito em primeira pessoa, a pintora-narradora comenta:

"Também tenho que te escrever porque tua seara é a das palavras discursivas e não o direto de minha pintura" (Lispector 5, pp. 10-11) .

"Escrevo-te como exercício de esbogos antes de pintar. Vejo palavras. 0 que falo é puro presente e este livro é uma linha reta no espaço. É sempre atual, e o fotômetro de uma máquina fotográfica se abre e imediatamente fecha, mas guardando em si o flash"' (id., ibidam, p. 19) .

Texto profundamente dramático, nas palavras de Benedito Nunes, escritura - aliás, "dura escritura", como declara a personagem-pintora de Água Viva -, "criação de sobrevida e aproximação da morte" (Nunes 9, p. 156) e "fluido quanto à matéria, Áqua Viva não tem outra história senão a do fluxo de uma meditação erradia, apaixonada, ao sabor da variação de certos temas gerais" (id., ibidem, p. 157). Sem enredo e sem personagens, podemos dizer que o texto narra as oscilações internas, vividas pela personagem-narradbrapintora, por êxtases e quedas, segundo motivos aparentemente desconexos, entre eles, o tempo, a morte, paisagens hipotéticas, Deus, suscitando um bailado de imagens e idéias-sensações, onde o devaneio e o sonho funcionam como "fantasia protetora". Este texto-improviso, como foi qualificado pela protagonista, foi, também por ela, associado a um caleidoscópio:

"Um instante me leva insensivelmente a outro e o tema atemático vai se desenrolando sem plano mas geométrico como as figuras sucessivas num caleidoscópio" (Lispector 5, p. 14). 
Sujeita à linearidade do signo lingüístico e ao caráter consecutivo da linguagem verbal, a narrativa de Água Viva, que conta com uma poderosa força do imaginário, pode representar a fulguração da "chispa temporal do instante", na ordem sucessiva, como ponderou Benedito Nunes (Nunes 9, p. 159) . A intenção declarada pela personagem-pintora de Água Viva de reter uma súbita iluminação ou epifania, num presente imóvel ou, ao menos, num tempo detido (vertical) e estabilizado, encontra, contudo, no ato de narrar ou na escritura, uma dupla dificuldade: a sua expansão no tempo (horizontal, linear) e a necessidade de ser lida, temporalmente. É neste sentido que se pode dizer, com Olga de Sá, que a personagem-narradora de Água Viva procurou, com seu discurso, no papel-tela-bloco de pedra, desenhar, pintar e esculpir ou, enfim, "fotografar uma escritura atemporal" (Sá 13, p. 96).

Mas para isto seria necessário abandonar e estar liberto das fomas plenas e do círculo fechado do pensar e se entregar a uma nova plenitude (Almeida 1, p. 6), inaugurando assim uma linguagem "redonda", "enovelada" e "tépida" (Lispector 5, p. 9) ; uma linguagem onde predominem as fomas desemolduradas, libertas do discurso (linear) e do narrativo que seguiria um plano, previamente elaborado; um texto-caleidoscópio onde, mais do que descrever fatos e acontecimentos, apresente, ao invés, "as cintilaçães de uma linguagem" (Motta Pessanha 8, p. xiii) que acompanhasse as vicissitudes de um tempo pontilhado de instantes únicos e que "não seguem a medida".

A importância do plano da narração, do ponto de vista do ato de narrar, em Água Viva, adquire um grande interesse devido à redução do enredo e à apresentação aleatória dos vários temas. Trata-se de um texto que foi considerado por Benedito Nunes "um caso extremo da experiência temporal na arte de narrar" (Nunes 11, p. 66), num anseio por fundir o tempo do enredo e o tempo da narração. Recusando a todo momento qualquer enredo ou história que poderia limitar o seu texto a uma construção prévia e dependente, a personagem, num dado momento, reconhece que sua escritura é "(...) atravessada de ponta a ponta por um frágil fio condutor - qual? 0 do mergulho na matéria da palavra? O da paixão? Fio luxurioso, sopro que aquece o decorrer das sílabas" (Lispector 5, p. 30) . Com isto, nomeamos o grande tema não apenas de Água Viva, mas de toda a obra de Clarice Lispector: a preocupação sempre com a própria natureza da linguagem. No entanto, o reconhecimento deste grande tema (o mergulho na matéria da palavra) equivaleria aceitar o aspecto discursivo da linguagem e a dificuldade de reproduzir em palavras certos momentos-epifânicos:

"É tão difícil falar e dizer coisas que não podem ser ditas. É tão silencioso. Como traduzir o silêncio do encontro real entre nós dois? Dificíl imo contar: olhei para você fixamente por uns instantes. Tais momentos são meu segredo. Eu chamo isto de estado agudo de felicidade" (Tispector 5, p. 63) .

"Atrás do pensamento atinjo um estado. Recuso-me a dividi-lo em palavras - e o que não posso e não quero exprimir fica sendo o mais secreto dos meus segredos" (id., ibidem, p. 85) .

Todavia, é preciso notar que, embora a personagem-narradora declare a dificuldade em "dizer coisas que não podem ser ditas", ela, efetivamente, jáo diz.

O ímpeto, enfim, da personagem-narradora em transformar a própria palavra em algo que seja um marco/posse (imagem de verticalidade), que seja capaz de atingir e fixar a essência/halo das coisas, evidencia-se ainda nesta bela passagem:

"O halo é vertiginoso. Finco a palavra no vazio descampado: é uma palavra com o fino bloco monolítico que projeta sombra" (id., ibidem, p. 56) .

A linha perpendicular representada pela palavra ("fino bloco monolítico"), fincada no "vazio descampado" (horizontalidade), não significaria, afinal, a dimensão poética (vertical) de uma fala criativa e inaugurante, capaz de oferecer ao homem a possibilidade de vencer o tempo que escorre 
e foge inexoravelmente para um fim (morte) ? Água Viva, mais do que tudo, vive, simultaneamente, a "voluptuosidade em ir criando o que dizer" e "a cerimônia da iniciação da palavra e meus gestos são hieráticos [Rainha egípcia!] e triangulares" (Mbtta Pessanha 8, p. 19) .

Abstract: The remarkable presence of a poetical prose in the fictional work of Clarice Lispector made possible to exemplify some central notions (vertical time and poetical instant) in the fertile and suggestive reflection of Gaston Bachelard about the poetical universe.

Key-words: vertical time - present time - poetical instant - poetical prose - literature

\section{Notas}

(1) Gilda de Mello e Souza, num artigo citado por Olga de Sá (Sá 13, p. 32), ressalta o fato de que Clarice, não respeitando o princípio da limitação dos gêneros, usa na ficção os processos da poesia (linguagem anímica, violentação do sentido lógico da frase, anotação do excepcional).

(2) Bachelard chama essas imagens-frases de sentenças poéticas, e não fragmentos, já que, para o autor, "o nome de fragmentos, utilizado pelos fragmentaristas, prejudica-os. Nada é partido numa imagem que encontra força em sua condensação" (Bachelard 2, p. 75).
(3) Olga de Sá (Sá 13) analisou, magistralmente, a escritura clariceana apontando a "metáfora estranhada" como sua característica mais evidente. Enfatizemos essa análise, pois, lembrando que a metáfora ocupa um lugar privilegiado na escritura clariceana.

(4) A partir de 1938, Bachelard irá se debruçar sobre os fundamentos da legitimidade do devaneio e do sonho, como atividades imorescindíveis, não só para a arte, mas para a própria vida. Nas palavras de Motta Pessanha, o pensador franaês conquista o direito de sonhar (Motta Pessanha 8, p. xi), o que deu título a uma coletânea póstuma Le Droit de Rêver.

(5) A sugestão de transcendência que pode advir daí foi entendida por Benedito Nunes, especialmente em se tratando de A Paixão segundo G.H., de Clarice Lispector, como "trans-descendência". Ver, a este respeito, Nunes 10, p. 138.

(6) Ver, a este respeito, Mbisés 7, pp. 5-6.

(7) Cirlot, no seu Dicionário de Símbolos (p. 57), comenta, entre outras interpretações, o aspecto de síntese que se pode aplicar a ouroboros, ou seja, a união entre dois princípios: ctônico (serpente) e o celeste (pássaro). Em sentido geral, esta imagem, seguindo o autor, simbolizaria o tempo e a continuidade da vida.

(8) Ao lado desta palavra, outras ainda foram usadas ("oratório", "escrínio", "sarcófago", "câmara-ardente"), num esforço revelado pela protagonista-narradora para exprimir a polivalência das sensações da personagem G.H. com relação ao quarto de empregada.

(9) Ver, a este respeito, Bachelard 3.

(10) Esta contorção se opera em nível da linguagem e é perceptível na sintaxe dos textos clariceanos, particularmente, em A Paixão. Eis alguns exemolos: "O mundo se me olha, tudo olha para tudo, tudo vive o outro; neste deserto, as coisas sabem as coisas" (Lispector 4, p. 87).

(11) Estamos nos referindo, basicamente, a Bachelard 3, fundamental para a compreensão da noşão bachelardiana de tempo vertical.

(12) A leitura das obras de Benedito Nunes, em especial Nunes 9, e de Olga de Sá (Sá 13) é fundamental para a compreensão da questão da linguagem em Clarice Iispector. 


\section{Bibliografia}

1. Almeida, A.M. de. O It/Id da Escritura. In: Minas Gerais, Belo Horizonte, 1ํ jun. 1935. Suplemento Literário, 974: 6-8.

2. Bachelard, G. A Chama de uma Vela. Trad. Glória de Carvalho Lins. Rio de Janeiro, Editora Bertrand Brasil, 1989.

3. _. Instant Poétique et Instant Métaphysique. In: L'Intuition de I'Instant. s.l., Gonthier, 1932.

4. Lispector, C. A Paixão segundo G.H. (rom.) . 5a ed. Rio de Janeiro, J.Olympio, 1977.

5. _. Água Viva (ficção). São Paulo, Círculo do Livro, s.d.

6. __ . O Lustre (rom.) . $4^{a}$ ed. Rio de Janeiro, Paz e Terra, 1976.

7. Moisés, M. Clarice Lispector: Introspecção e Lirismo. In: O Estado de S. Paulo, São Paulo, 20 jul. 1991, Cultura 8 (571) p. 5-6.

8. Motta Pessanha, J. A. Introdução. In: Bachelard, G. O Direito de Sonhar. Trad. José Américo Motta Pessanha et al., $2^{a}$ ed., São Paulo, Difel, 1986.

9. Nunes, B. O Drama da Linguagem. Uma Leitura de Clarice Lispector. São Paulo, Ática, 1989.

10. _ O Imaginário em Clarice Lispector. In: O Dorso do Tigre. 2ª ed. São Paulo, Perspectiva, 1976.

11. _ _ o Tempo na Narrativa. São Paulo, Ática, 1988.

12. Paz, O. A Imagem. In: O Arco e a Lira. Trad. Olga Savary. Rio de Janeiro, Nova Fronteira, 1982.

13. Sá, O. de. A Escritura de Clarice Lispector. Petrópolis-RJ, Vozes; LorenaSP, Fatea, 1979. 